\title{
Laboreal
}

Volume $14 \mathrm{~N}^{\circ} 1$ | 2018

O regresso ao emprego após um acidente de trabalho

\section{A reconstituição de experiências após um acidente de trabalho: mapas de percurso como instrumento de análise}

La reconstitución de experiencias tras un accidente de trabajo: mapas de trayectoria como instrumento de análisis

La reconstruction d'expériences après un accident du travail: des cartes de parcours comme instrument d'analyse

The reconstruction of experiences after a work accident: accident journey charts as assessment instruments

\section{Cláudia Pereira e Vanessa Rodrigues}

\section{OpenEdition}

\section{Journals}

\section{Edição electrónica}

URL: http://journals.openedition.org/laboreal/473

DOI: $10.4000 /$ laboreal.473

ISSN: 1646-5237

\section{Editora}

Universidade do Porto

\section{Refêrencia eletrónica}

Cláudia Pereira e Vanessa Rodriques, « A reconstituição de experiências após um acidente de trabalho: mapas de percurso como instrumento de análise », Laboreal [Online], Volume $14 \mathrm{~N}^{0} 1 \mid 2018$ posto online no dia 01 julho 2018, consultado o 07 outubro 2019. URL : http:// journals.openedition.org/laboreal/473 ; DOI : 10.4000/laboreal.473

Este documento foi criado de forma automática no dia 7 outubro 2019

\section{cc) ()}

Laboreal está licenciado com uma Licença Creative Commons - Atribuição-NãoComercial 4.0 Internacional. 


\section{A reconstituição de experiências após um acidente de trabalho: mapas de percurso como instrumento de análise}

La reconstitución de experiencias tras un accidente de trabajo: mapas de trayectoria como instrumento de análisis

La reconstruction d'expériences après un accident du travail: des cartes de parcours comme instrument d'analyse

The reconstruction of experiences after a work accident: accident journey charts as assessment instruments

Cláudia Pereira e Vanessa Rodrigues

\section{NOTA DO EDITOR}

http://dx.doi.org/10.15667/laborealxiv0118cp

Manuscrito recebido em: dezembro/2017

Aceite após peritagem: abril/2018

\section{Acidentes em contexto laboral e o regresso ao trabalho: algumas referências teóricas e metodológicas}

Os acidentes de trabalho constituem um fenómeno social produtor de inúmeros impactos, desde logo na vida daqueles que os sofrem, mas também na organização e atividade de outros agentes sociais e instituições direta ou indiretamente ligadas à 
sinistralidade laboral - empregadores, serviços do Estado, seguradoras, famílias dos sinistrados e outros grupos e contextos sociais com que os sinistrados interagem e se relacionam. O seu 'carácter permanente e massivo' (Pinto, 1996, p. 92) tem sido, nos últimos anos, reforçado por um aumento associado à sua ocorrência (193 611 acidentes de trabalho foram registados em 2012 e, num quadro de evolução constante de aumento, em 2015 ['] registaram-se 208 457).

2 Existe um conjunto diverso de conhecimentos produzidos em várias áreas científicas que se dirigem a esta temática e que incide, nomeadamente, sobre: a prevenção, a análise do risco e das causas dos acidentes de trabalho [2]; a compreensão dos processos de reabilitação e reintegração socioprofissional dos trabalhadores acidentados [3]; a análise das suas expectativas no regresso ao trabalho [4]; o papel dos colegas de trabalho após um acidente [5]; ou até sobre o período de ausência ao trabalho provocado pelo acidente [ $\left.{ }^{6}\right]$. Os projetos de pesquisa que estão na base destes estudos contemplam a utilização duma variedade de técnicas de investigação e, ainda que privilegiando metodologias de cariz qualitativo (recorrendo a entrevistas, recolha e análise documental, histórias de vida), fazem também uso de dados estatísticos (disponíveis nas fontes oficiais ou recolhidos propositadamente para o estudo em questão).

3 Não obstante o património acumulado, exemplificado nas referências que aqui se mencionaram, uma abordagem menos presente na produção científica tem sido a análise dum percurso pós-sinistro que contemple a compreensão das etapas subsequentes ao acidente de trabalho, integrando elementos relativos à interação com as instituições responsáveis pelo processo de reparação (e.g. Companhia de Seguro; Tribunal do Trabalho) [7], aos facilitadores e obstáculos que surgem no decorrer do mesmo, à interação com outros agentes, assim como aos sentimentos vivenciados pelos sinistrados no decorrer do leque de experiências que formam esta trajetória [ $\left.{ }^{8}\right]$. Esta 'ordem de interação' (Goffman, 1983) com as estruturas sociais tem vindo a ser objeto de estudo para alguns autores (Dubois, 1999; Siblot, 2006) que, através de incursões etnográficas, procuraram compreender as políticas públicas através do estudo dos momentos de encontro entre as instituições e os indivíduos, e cujas obras inspiraram à compreensão dos percursos pós-sinistro e das suas vicissitudes. Métodos de reconstituição de percursos são largamente utilizado no âmbito das ciências sociais, com graus de complexificação e suportes teóricos diversificados, em forma, entre outras designações, de histórias de vida, biografias, estudo de trajetórias e percursos. Com um enfoque analítico direcionado a um percurso pós-sinistro, a abordagem que aqui se apresenta não se aproxima duma lógica puramente biográfica, de uma trajetória como sendo uma 'sequência de posições ocupadas por um mesmo agente (ou um mesmo grupo)' sem relação com o seu 'contexto em constante transformação' e com 'o conjunto das relações objetivas' entre os vários intervenientes (Bourdieu, 1986, p. 71-72).

4 De forma complementar à lógica da trajetória até aqui abordada, destaca-se (de forma sucinta) um estudo realizado sobre o processo de reinserção social e profissional de trabalhadores em fase de readaptação física, social e profissional (Baril, Martin, Lapointe \& Massicotte, 1994), cujos contributos teóricos auxiliam na compreensão da utilização dos mapas de percurso: trata-se de um estudo exploratório, realizado no Québec, cujos objetivos se prendiam com a identificação de fatores que facilitam ou criam um obstáculo à reinserção profissional de trabalhadores com uma incapacidade 
profissional permanente, em fase de readaptação física, social e profissional; o desenvolvimento de um modelo de compreensão global da reinserção profissional e social; e a identificação de pistas para pesquisa futura e intervenção. Com os resultados obtidos, através da recolha e análise de dados estatísticos, da análise de informação sobre os trabalhadores, e da realização de entrevistas semi-diretivas com estes e outros atores sociais (e.g. empregadores, sindicatos), foi identificado um modelo conceptual que integrou a trajetória ocorrida depois da lesão (que inclui, a título de exemplo, os momentos da análise e avaliação médica, da procura de emprego e do processo de reparação legal), o percurso destes trabalhadores (que se reporta, por sua vez, à vivência desses momentos e respetiva atribuição de significados), as interações sociais, e o seu itinerário pessoal. A análise de diversos fatores (pessoais, administrativos, legais, médicos, profissionais, sociais) permitiu, então, compreender a diversidade e complexidade de elementos que interagem num processo de readaptação após um acidente de trabalho.

\section{Os acidentes de trabalho como bifurcações, as trajetórias e percursos consequentes}

5 Os acidentes de trabalho podem ser definidos como 'acontecimentos inesperados e imprevistos, incluindo atos derivados do trabalho ou com ele relacionados, do qual resulte uma lesão corporal, uma doença ou a morte de um ou vários trabalhadores' (Gabinete de Estratégia e Planeamento, 2010, p. 15). Neste sentido, os acidentes podem ser encarados como um evento de saúde, apresentando um carácter imprevisível para os indivíduos (Testenoire \& Trancart, 2011). O momento da ocorrência do acidente, corresponde a uma rutura ["] (Testenoire \& Trancart, 2011; Quériaud, Dugué \& Petit, 2015), tornando-se num processo, de certo modo incerto, em relação à evolução do problema de saúde derivado do acidente (e.g. lesão músculo-esquelética), ao regresso profissional (e.g. regresso ao mesmo emprego, adaptação do posto de trabalho) e sobre as consequências que o evento pode ter a outros níveis (e.g. a nível pessoal, social, familiar) (Testenoire \& Trancart, 2011).

6 Este tipo de acontecimentos, provoca, na maior parte das vezes, uma ausência ao trabalho (curta ou prolongada), sendo que, pelas consequências que o acidente pode provocar (e.g. a nível físico, psicológico) e por ser encarado, por alguns autores, como um facto social que envolve uma dimensão física, psicológica, social (Martin \& Baril, 1995), corresponde a um ponto de inflexão, ligado a um 'antes' e a um 'após', que envolve um tempo de readaptação (Quériaud et al., 2015). Neste sentido, o acidente (e a ausência ao trabalho) pode também ser encarado como uma bifurcação [ $\left.{ }^{10}\right]$ (Quériaud et al., 2015; Hélardot, 2006). De acordo com Hélardot (2006), as bifurcações correspondem a uma 'modificação brutal, imprevista e duradoura da articulação biográfica entre a esfera de saúde e trabalho, desde que essa modificação seja desenhada pelos atores envolvidos como um ponto de inflexão ligado a uma distinção entre um 'antes' e um 'depois" (p. 66) e podem ser conotadas de forma positiva ou negativa, tendo em conta a significação atribuída pelos indivíduos, embora os efeitos negativos sejam os mais frequentes (Testenoire \& Trancart, 2011; Hélardot, 2006).

7 Estas bifurcações consistem, então, numa redefinição das orientações que podem ocorrer num determinado momento no percurso, sendo que a análise se centra na maneira como os atores procedem à interpretação do seu percurso e constroem o 
significado da sua experiência (Hélardot, 2006). Neste sentido, e explorando os conceitos abordados por Baril et al. (1994) - trajetória e percurso -, esta interpretação do seu caminho e construção de significado da experiência, pode então ser entendida como o percurso. É neste percurso que se inclui a experiência pessoal, sendo recuperada através do discurso dos indivíduos, e a sua reconstrução não se efetua necessariamente de forma integral, sequencial e recuperando todos os detalhes associados ao processo, mas sim, através da recuperação de determinados momentos e experiências que constituíram significado para os indivíduos (Baril et al., 1994). Assumindo que a recuperação de vivências anteriores, neste caso um acidente de trabalho, é vivido como uma experiência de confronto consigo próprio, é, na maior parte das vezes, também o primeiro momento em que o indivíduo reflete sobre o processo do acidente em si (Dubar, 1998). Neste sentido, constrói a partir das suas perceções e representações um significado que lhe permite desenvolver estratégias no percurso pós-sinistro. 0 processo de produção do significado é então dinâmico e está em constante interação com aquilo que compõe a realidade social do indivíduo (Baril et al., 1994). O que acompanha este percurso corresponde então à trajetória pelo universo legal e administrativo que enquadra os trabalhadores a partir do momento em que o evento de saúde acontece até à sua readaptação, à reinserção social e profissional, privilegiando uma perspetiva mais factual e prescrita associada ao processo (Baril et al., 1994).

8 Numa fase exploratória do estudo 'Regresso ao trabalho após o acidente: superar obstáculos' - que se apresentará no ponto seguinte - a reconstituição das experiências após um acidente de trabalho apresentada em mapas de percurso dirige-se, precisamente, a este desdobramento das vivências dos sinistrados em elementos objetivos e subjetivos, à trajetória e ao percurso, não com intenção de desligar os aspetos de um e outro enquadramento, mas, pelo contrário, de os evidenciar de forma relacional.

Assim, e conforme será explorado no presente texto, esta reconstituição de experiências, ainda que contemple elementos relativos ao regresso ao trabalho, remetese essencialmente à compreensão do percurso institucional que os sinistrados percorreram e à exploração do modo como estes se relacionaram com as diferentes instituições responsáveis pela efetivação dos direitos resultantes de um acidente de trabalho (nomeadamente com as entidades empregadoras, as companhias de seguros e o Tribunal do Trabalho), assim como com outros agentes sociais, sejam instituições ou não, e cujos contactos terão sido ativados no sentido de resolver obstáculos que surgiram nestes percursos.

\section{Mapas de percurso: da conceção do instrumento aos desafios e potencialidades associados à sua utilização}

\subsection{Enquadramento da sua conceção e utilização}

10 No âmbito do projeto de investigação 'Regresso ao trabalho após o acidente: superar obstáculos' [11], que teve por objetivo principal conhecer e compreender os percursos após um acidente de trabalho no contexto português, bem como as consequências que estes eventos de saúde podem provocar nos sinistrados a nível profissional, familiar, 
social e pessoal, foram construídos, numa fase exploratória do estudo, um conjunto de mapas de percurso que ilustram as trajetórias e os percursos de alguns acidentados. Trata-se de um instrumento de observação, inicialmente desenvolvido na área do marketing - os costumer journey maps $\left[{ }^{12}\right]$ - para o apuramento da mobilidade e satisfação de consumidores. No âmbito da investigação sobre o regresso ao trabalho após um acidente, este instrumento foi concebido enquanto ferramenta de comunicação visual $\left.{ }^{13}\right]$ que tem como principal objetivo facilitar a compreensão das interações entre os indivíduos e as instituições, partindo do ponto de vista do sinistrado [14]. Para a construção dos mapas de percurso foram realizadas entrevistas individuais com sinistrados, que permitiram a recolha de informações relativas a percursos diferenciados decorrentes de um acidente de trabalho, e que se exploram de seguida no ponto 3.2.1.

11 Não obstante a sua proveniência da área do marketing, o conteúdo que dá forma à sua estrutura é conseguido através de entrevistas individuais de restituição de experiências de vida relacionadas com determinadas entidades - no caso aqui em análise, as experiências estão centradas nas interações entre os indivíduos e as instituições com as quais interagiram após a ocorrência do acidente de trabalho. Como já mencionado no enquadramento teórico-metodológico, as experiências e histórias de vida são elementos igualmente presentes e trabalhados nas ciências sociais, nomeadamente quando há recurso a técnicas como as entrevistas biográficas ou compreensivas. E, na medida em que permitem o acesso a representações subjetivas, às histórias, aos percursos e vivências dos indivíduos (Kaufmann, 1996), estas entrevistas visam a reconstrução do percurso de vida, sendo que as experiências vividas são recuperadas de acordo com o significado e pertinência que tiveram no indivíduo (Zaccaï-Reyners, 1995), por ser o participante entrevistado a dirigir o conteúdo explorado (Blanchet \& Gotman, 1992, cit in Ramos, 2006).

Numa lógica de complementaridade metodológica e num esforço de situar as trajetórias dos sinistrados em relação às condições concretas da sua existência (Bourdieu, 1986), a construção dos mapas surge ancorada na estrutura de investigação do estudo, cujas etapas se encontram na Figura 1. Neste trabalho, privilegiou-se uma abordagem metodológica mista, com uma primeira fase sobretudo qualitativa, de recolha e análise documental (legislação sobre percurso pós-sinistro; estatísticas nacionais sobre os acidentes de trabalho), de realização de entrevistas individuais a sinistrados, e da elaboração dos mapas de percurso; e uma segunda fase, sobretudo quantitativa, com a construção e aplicação do inquérito por questionário a 366 sócios e ex-sócios da Associação Nacional dos Deficientes Sinistrados no Trabalho (ANDST), a nível nacional, seguidas da respetiva análise dos dados (realizada através do programa de tratamento de dados estatísticos SPSS - Statistical Package for the Social Sciences) e apresentação de resultados do estudo [15]. 
Figura 1: Identificação das principais etapas do projeto de investigação 'Regresso ao trabalho após o acidente: superar obstáculos', realizado entre maio de 2016 e março de 2017

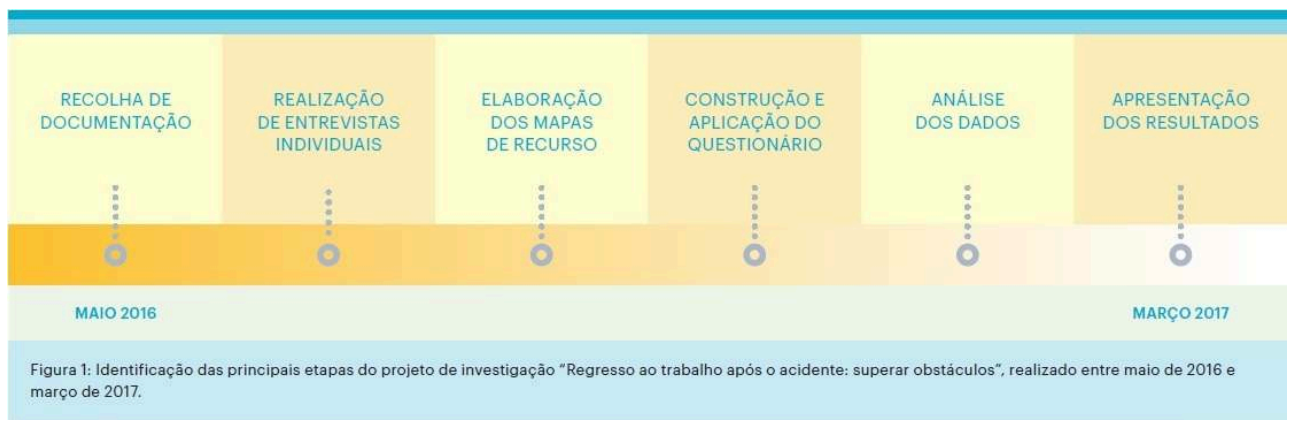

\subsection{Processo de construção dos mapas de percurso}

\subsubsection{As entrevistas individuais com os sinistrados}

A produção dos mapas de percurso no âmbito deste projeto - 10 mapas elaborados no total -, conforme já foi salientado, apenas se tornou possível com o recurso às entrevistas individuais realizadas junto de sinistrados do trabalho, sócios e ex-sócios da ANDST, cujos acidentes ocorreram há aproximadamente 10 anos. A seleção dos indivíduos foi feita com recurso à direção e aos técnicos da ANDST com base nas variáveis género e grau de incapacidade. Ainda que este corpus de entrevistas não tenha sido constituído sob a forma de amostra representativa, por não ser esse o objetivo do exercício em questão, através duma tentativa de distribuição que se aproximasse ao comportamento destas variáveis na realidade nacional dos sócios e ex-sócios da ANDST, procurou-se chegar a trajetórias variadas, permitindo, assim, uma compreensão mais ampla e aprofundada dos percursos e da sua diversidade $\left.{ }^{[16}\right]$.

Estas entrevistas (realizadas com suporte de gravação áudio e com uma duração média de uma hora e trinta minutos por entrevista), procuraram incidir essencialmente sobre a compreensão das trajetórias e percursos após um acidente de trabalho. 0 guião que orientou a condução destas entrevistas, realizadas por dois dos investigadores do projeto, inspirou-se na própria estrutura do mapa de percurso (ver secção 3.2.2.), podendo estas entrevistas ser classificadas como semi-diretivas, cujas questões-guia, foram sendo geridas em função do discurso dos participantes.

\subsubsection{A estrutura dos mapas de percurso}

15 No que diz respeito à sua estrutura (ver Figura 2), os mapas de percurso apresentam na parte superior uma breve caracterização do sinistrado, constituída por elementos como o género, a idade, o nível de escolaridade, o local de residência, a data do acidente, a parte do corpo atingida/lesão, o grau de incapacidade, uma breve descrição do acidente, a profissão atual e algumas indicações relativas ao percurso profissional.

Procurou-se, no decorrer da entrevista de reconstituição do percurso pós-acidente, que o participante partilhasse todos os momentos de interação no seu percurso póssinistro, desde o momento do acidente ao último encontro institucional. O conteúdo recolhido nestas entrevistas (discurso dos participantes) encontra-se, então, refletido no mapa, de modo sequencial. Aos momentos que se registaram, com base no discurso dos participantes, adicionou-se uma linha temporal, feita através da identificação, 
sempre que possível, da duração de cada momento, assim como dos intervalos temporais entre estes. Assim, o tamanho dos 'nós' desta linha reflete proporcionalmente a duração desses intervalos (quanto maior o tamanho do nó, maior o intervalo de tempo entre um momento e outro).

Sobre cada um dos momentos de contacto institucional do percurso pós-sinistro, o mapa integra cinco campos, recuperados da estrutura original utilizada na área do marketing. De seguida, descrevem-se e ilustram-se estes campos com exemplos do mapa de percurso apresentado na Figura 2:

- as atividades concretas que tiveram lugar no percurso pós-sinistro de cada indivíduo, isto é, onde decorreram, o que nelas ocorreu, que ações foram levadas a cabo e por quem, se o momento de contacto identificado foi de carácter obrigatório ou por iniciativa própria (e.g. contactos com a seguradora e encaminhamento para fisioterapia; contacto com Tribunal do Trabalho). Ressalva-se que atividades mencionadas pelos entrevistados sobre as quais não foi possível obter informação relativa aos cinco campos do mapa, ou informações adicionais sobre os momentos de contacto, encontram-se destacados de forma autónoma em cima da linha temporal e a esta associados (e.g. solicitação de apoio junto da ANDST, ao longo do processo por parte do participante);

- os canais de comunicação/interfaces utilizados para essas atividades, e devidamente identificados com ícones associados a cada canal de comunicação (e.g. receção de cartas das entidades ou contacto telefónico) e interface (e.g. contactos com médicos, contactos com o Procurador);

- os facilitadores e obstáculos encontrados nessas atividades, sendo que assinalado a verde, e com o símbolo de avançar ('play'), estão destacados os facilitadores - aspetos que tornaram o processo menos penoso, que auxiliaram/facilitaram na resolução do processo e reintegração pós-acidente (e.g. apoio prestado pela família e pela ANDST) e assinalado a azul, com o símbolo de pausa, estão destacados os obstáculos - elementos encarados como constrangimentos, que dificultaram a resolução do processo e reintegração pós-acidente (e.g. o facto da entidade empregadora não ter celebrado um seguro de acidentes de trabalho válido e não ter acompanhado o processo);

- os sentimentos e experiências positivos, destacados a verde (e.g. a satisfação em relação aos cuidados médicos prestados, nomeadamente na fisioterapia) e os negativos, destacados a vermelho (e.g. a revolta em relação à postura assumida pela entidade empregadora);

- e, por fim, as sugestões de melhoria relativas a cada atividade mencionada. No caso do mapa apresentado na Figura 2 não foram identificadas, pelo participante, sugestões de melhoria; no entanto, e a título de exemplo para conhecimento, identificam-se algumas sugestões partilhadas por outros participantes: a existência de um momento de preparação para o contacto com o Tribunal do Trabalho; a garantia da imparcialidade dos peritos médicos das companhias de seguro.

Estes campos que estruturam o mapa permitiram, para além de uma análise completa de cada momento de interação e numa perspetiva sincrónica (lida em coluna), uma análise transversal de cada uma delas, numa perspetiva anacrónica (lida em linha), percebendo-se que estas histórias e bifurcações expõem dois níveis de realidade que não devem ser dissociados: os factos objetivos e os factos que decorrem de perceções, representações e interpretações subjetivas e das suas transformações ao longo do percurso (Hélardot, 2006). Por outras palavras, e recuperando os conceitos introduzidos inicialmente, este instrumento permitiu recuperar, por um lado, a trajetória após o acidente - identificação da data da ocorrência do acidente, dos períodos de tempo de 
baixa ou em fisioterapia, dos momentos de contacto no Tribunal do Trabalho, do momento de regresso ao trabalho; e, por outro lado, os percursos levados a cabo por estes indivíduos - as suas experiências e sentimentos em cada uma das fases, a identificação daquilo que facilitou ou dificultou o processo após o acidente de trabalho.

Figura 2. Mapa de percurso, relativo a um dos participantes entrevistados

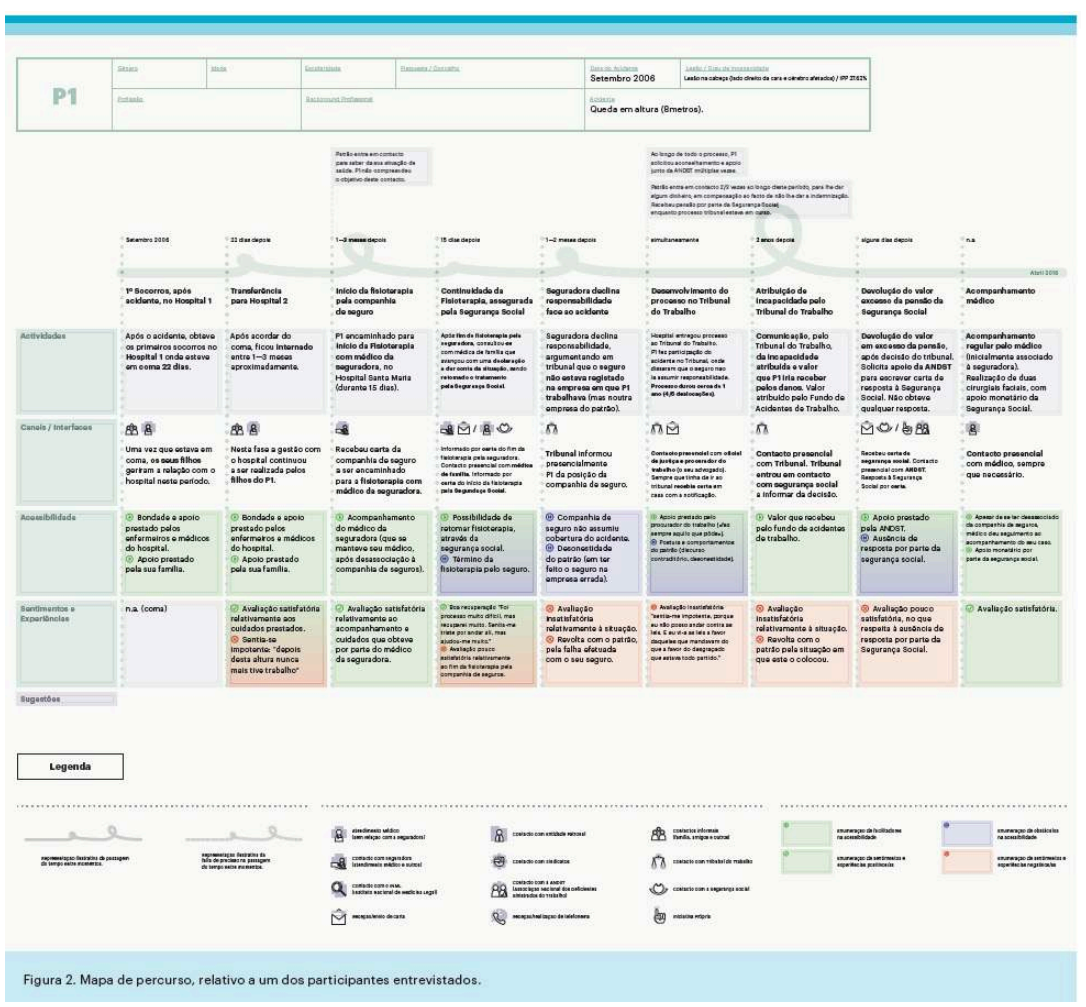

\subsection{Desafios e potencialidades associados à utilização dos mapas de percurso}

A utilização dos mapas de percurso, no âmbito da investigação 'Regresso ao trabalho após o acidente: superar obstáculos' permitiu identificar alguns desafios que podem surgir no recurso a este instrumento, e que se associam essencialmente ao investigador e ao participante (da entrevista).

No que respeita aos desafios associados ao papel do investigador, é de salientar a necessidade de se manter uma escuta ativa ao longo do momento de entrevista que incorpore uma atenção dirigida aos vários aspetos partilhados pelos entrevistados, bem como privilegiar uma postura de flexibilidade associada ao guião e, consequentemente, à condução da entrevista. Pelo facto de o guião ser estruturado em função da estrutura do mapa de percurso, a capacidade de acompanhar o discurso dos participantes, centrado na reconstrução da sua trajetória e percurso, e de assegurar a exploração de detalhes e referências temporais mencionadas, numa tentativa de obter informação relativa aos cinco campos do mapa, e sobre cada atividade identificada, revelou-se, de facto, como um desafio. Este está associado, essencialmente, ao facto - já mencionado de os sinistrados recuperarem da sua história apenas os aspetos significativos e, uma vez que para todos eles foi a primeira vez que refletiram sobre esta inflexão na sua vida 
- o acidente - tentando partilhar, brevemente, o 'antes' (sua situação profissional, social, pessoal antes do acidente), e, com mais detalhe, o 'após' (contacto com entidades legais, o regresso ao trabalho), o discurso, por vezes, variava, em termos de profundidade/detalhe, de clareza e de recuperação temporal do processo.

Para além disso, é de referir que o entrevistador, apesar de procurar 'cumprir' as questões do guião e manter uma preocupação na recolha de elementos conducente com a estrutura do mapa, deve procurar garantir, nomeadamente na transcrição da entrevista, as expressões e as preocupações dos sinistrados, evitando, assim, a descontextualização das informações partilhadas e preservando a riqueza do discurso dos entrevistados (Mendes, 2003). Ora, esta transcrição das informações para a estrutura dos mapas de percurso pode tornar-se num desafio, uma vez que se trata de um elemento visual e esquemático, no qual devem apenas constar as principais informações, procurando-se preservar esta referida riqueza do discurso dos participantes.

Relativamente ao que se pode considerar como um desafio para o próprio participante (neste caso um sinistrado do trabalho), salienta-se a dificuldade, percecionada no momento de entrevista, em recuperar temporalmente cada acontecimento associado ao acidente. Apesar do esforço evidenciado pelos participantes em organizarem o seu discurso de forma sequencial, tentando reconstituir o seu percurso pelo momento do acidente de trabalho, as atividades ocorridas após este acontecimento vão sendo recuperadas e partilhadas em função da importância e significado que tiveram para o sinistrado. A título de exemplo, pode perceber-se que determinados acontecimentos relacionados diretamente com a reparação legal na sequência de um acidente de trabalho (e.g. contacto com a companhia de seguros ou com o Tribunal do Trabalho), apesar de terem sido concretizados, mas não terem tido impacto (positivo ou negativo) para o sinistrado, acabaram ou por não ser mencionados, ou por serem revelados apenas após interpelação direta do entrevistador (que acabou por trazer o acontecimento à memória), o que nem sempre foi acompanhado com a precisão temporal da sua ocorrência e durabilidade.

Para além destes desafios que se tornaram possíveis identificar com base no trabalho de terreno realizado com as entrevistas individuais e consequente elaboração dos mapas de percurso, é também de salientar algumas potencialidades associadas à utilização do instrumento em análise e centradas na sua representação gráfica e esquemática.

24 Este tipo de mapeamento de percurso revelou-se particularmente profícuo numa fase exploratória - neste caso, na fase de elaboração de questões para o questionário que foi concebido no estudo -, ao permitir a descrição e caracterização do percurso de relacionamento com as instituições e outros agentes sociais através de uma forma visual, esquemática e intuitiva. Neste sentido, este instrumento revela-se como uma ferramenta útil para a construção de instrumentos de inquirição mais próximos e contextualizados sobre a realidade vivenciada pelos indivíduos. 0 facto de se tratar de uma apresentação gráfica, e que implica uma sistematização da informação que se circunscreva a momentos e palavras-chave, permite ao investigador ter um acesso facilitado às principais atividades ocorridas ao longo do percurso, bem como à dimensão temporal que o reveste.

Pela sua estrutura, integradora de uma trajetória e de um percurso (Baril et al., 1994), de factos objetivos e de factos que decorrem de perceções, representações e interpretações subjetivas e das suas transformações ao longo do percurso dos participantes (Hélardot, 
2006), este instrumento tornou possível uma reconstituição temporal de uma história e de um evento de saúde (mesmo que incompleta, do ponto de vista factual) e uma melhor compreensão do seu impacto na vida dos acidentados (no percurso institucional, nas interações que tiveram, e nos sentimentos e emoções experienciados). Assim, os mapas de percurso construídos permitiram compreender o processo após o acidente, com base no discurso dos sinistrados, no que respeita ao contacto com diversas instituições legais até ao momento do regresso ao trabalho, explorando-se os canais de comunicação, as experiências e sentimentos, os elementos facilitadores e que dificultaram o processo, e eventuais propostas de melhoria.

É de relembrar que o conteúdo presente nos 5 campos do mapa surgem do discurso dos sinistrados, e correspondem aos aspetos mais significativos para estes participantes. E, se por um lado se revelou um desafio (para o próprio participante) a dificuldade em recuperar temporalmente cada acontecimento associado ao acidente, por outro lado, pode considerar-se uma potencialidade o facto de o instrumento ressaltar os aspetos que mais impacto tiveram na experiência individual do participante.

Ademais, e uma vez que este instrumento implica a exploração das várias dimensões descritas no ponto anterior (3.2.2.), o produto final reúne, sobre uma mesma atividade, conteúdo rico e variado tanto sobre as questões mais formais que enquadram este tipo de percurso, como dirigido a uma dimensão mais subjetiva, ligada à vivência concreta destas experiências. Permitem, assim, realçar valorizações emocionais e racionais, além de identificar as dificuldades encontradas ao longo do percurso e identificar sugestões de melhoria que surgem diretamente das mesmas.

\section{Reflexões finais: os mapas de percurso como instrumento facilitador para a reconstituição e análise de experiências após um acidente de trabalho}

28 A elaboração dos mapas de percurso na investigação 'Regresso ao trabalho após o acidente: superar obstáculos' permitiu, desde logo, cumprir o principal objetivo subjacente à sua utilização na investigação: compreender o processo vivenciado pelos sinistrados de trabalho, possibilitando a elaboração de um conjunto de questões adequadas à realidade dos percursos após um acidente (e.g. sobre o tipo de contactos: dificuldades vivenciadas) a serem integradas no questionário que permitiu caracterizar as circunstâncias e consequências de um acidente de trabalho a nível nacional.

Compreendeu-se que este processo, ainda que enquadrado legalmente (um processo prescrito a ser cumprido), apresenta um grau de variabilidade, que ao não ser apenas ditado pelo acidente em si, está igualmente associado aos momentos de contacto formal que ocorrem na sequência da sua reparação, nomeadamente em relação à duração associada a esse percurso, à condução do processo levado a cabo pelos agentes institucionais e, ainda, à forma como tudo é vivenciado pelos sinistrados. E relações com um mesmo agente que interfere nestas trajetórias podem ser experienciadas como facilitadoras por alguns indivíduos, ou constituírem-se como obstáculos no percurso de outros. Por exemplo, a postura assumida pela entidade empregadora após o acidente que, para alguns participantes, se enquadrou como um facilitador através de um acompanhamento e suporte; mas para outros participantes foi um dos principais obstáculos ao longo do percurso e no regresso ao trabalho). Apesar da literatura 
evidenciar (conforme explorado anteriormente) que a estes eventos de saúde - os acidentes - estão, por vezes, mais associados percursos que refletem o seu efeito negativo (Testenoire \& Trancart, 2011; Hélardot, 2006), tornou-se visível que não apenas são identificados, pelos participantes, impactos negativos (e.g. ausência de apoio por parte da entidade empregadora ou dos colegas de trabalho no regresso ao trabalho; ou despedimento), como também o são os facilitadores presentes ao longo do processo (e.g. o acompanhamento obtido por parte dos médicos na fase de Fisioterapia; ou o suporte familiar).

30 A leitura dos mapas de percurso permite reforçar a ideia de uma bifurcação associada ao acidente, tornando evidente que os percursos após um acidente de trabalho são complexos, incluem diversos obstáculos e conjugam fragilidades de várias ordens. Desde os distintos pontos de partida dos indivíduos e as características dos acidentes, até à duração do próprio percurso, ao tipo de acompanhamento que obtiveram ou não, ao conjunto de consequências destas ocorrências, às interações com as instituições e os profissionais que as representam, tudo se conjuga na formulação destes trajetos, cuja análise mais aprofundada permitirá reunir elementos de reflexão cruzados e pormenorizadamente fundamentados.

31 Um outro aspeto que importa também mencionar, e que se apresenta aqui enquanto sugestão para investigaç̃os futuras, diz respeito à integração no processo metodológico de um momento de validação e de restituição dos dados dos mapas de percurso aos participantes. Apesar de não ter sido concretizado no âmbito do estudo, reconhece-se a importância de um momento de restituição das informações junto dos indivíduos, nomeadamente pela entrevista se poder assumir como um desafio, tanto para estes como para o investigador, como assim o foi explorado (e.g. dificuldade em aceder a uma reconstituição sequencial dos acontecimentos; discurso dos participantes mais ou menos claro e detalhado). A concretização de um momento destes permitiria sustentar um novo processo de reflexão sobre o percurso pós-acidente, validando e complementando informações, com o auxílio de um instrumento de mediação (Rabardel, 1995) entre o sujeito e o percurso (e sua reconstituição) - o mapa.

32 Considera-se ainda que, apesar de os mapas de percurso se tratarem de um instrumento inicialmente utilizado na área do marketing, após serem devidamente ajustados de acordo com o objetivo do estudo, evidenciaram-se como um instrumento de trabalho, neste caso exploratório, com potencialidade de utilização noutras áreas, nomeadamente nas ciências sociais (e.g. Psicologia, Sociologia), pelo seu carácter 'maleável' no que respeita às temáticas que permite abordar. Neste caso, os mapas de percurso foram utilizados no âmbito de um estudo sobre as circunstâncias dos acidentes de trabalho e suas consequências para os indivíduos, mas considera-se viável a sua utilização noutras temáticas que englobem na sua análise a compreensão de percursos. Paralelamente, e não obstante as opções metodológicas do estudo em questão (inquérito por questionário como elemento central e as entrevistas e mapas como elementos de suporte prévio), considera-se que os mapas de percurso, para além de poderem ser utilizados enquanto instrumento exploratório - como aqui se analisou , podem também constituir-se como elemento metodológico principal duma pesquisa, podendo ser mais ou menos extensos e mais ou menos desenvolvidos e aprofundados em função dos objetivos que enformam os projetos de investigação.

Por fim, e ainda que já exista um conjunto de estudos sobre os acidentes de trabalho e sobre o processo de regresso ao trabalho, com desenhos metodológicos que incorporam 
uma diversidade de técnicas (conforme referências no enquadramento teórico inicial), os mapas de percurso parecem assumir-se como um instrumento diferenciador de exploração desta temática. A sua vertente diferenciadora está relacionada com o facto de o instrumento permitir uma reconstrução temporal dos processos individuais e uma eventual identificação de pistas de intervenção sobre a realidade a que se reportam (potenciada, entre outras coisas, pela perspetiva anacrónica e sincrónica que incorporam). Estas pistas poderão ser alvo de reflexão por parte de intervenienteschave com atuação na área dos acidentes de trabalho e suas consequências a nível pessoal, familiar, social e profissional, de forma a identificar potenciais ações de transformação do processo pelo qual passam os sinistrados do trabalho.

\section{BIBLIOGRAFIA}

Areosa, J. (2010). Riscos e sinistralidade laboral: um estudo de caso em contexto organizacional. Tese de Doutoramento, ISCTE - Instituto Universitário de Lisboa, Lisboa. http://cics.uminho.pt/wpcontent/uploads/2011/06/Jo\%C3\%A3o-Areosa-Tese-de-Doutoramento1.pdf

Areosa, J. (2012). A importância das perceções de riscos dos trabalhadores. International Journal on Working Conditions, 1, 3, 54-64. http://hdl.handle.net/1822/20167

Baril, R., Martin, J.C., Lapointe, C., \& Massicotte, P. (1994). Étude exploratoire des processus de réinsertion sociale et professionnelle des travailleurs en réadaptation. Institut de recherche en santé et en sécurité du travail du Québec. https://www.irsst.qc.ca/media/documents/PubIRSST/ RR-082.pdf

Baril, R. (2002). Du constat à l'action: 15 ans de recherché en réinsertion professionnelle des travailleurs au Québec. Perspectives interdisciplinaires sur le travail et la santé, 4, 2, 1-28. https:// doi.org/10.4000/pistes.3661

Barros-Duarte, C. \& Cunha, L. (2014). Para uma construção da prevenção de riscos profissionais: atividade de trabalho no centro da análise. In H. V. Neto, J. Areosa, \& P. Azeres (Eds.), Impacto Social dos Acidentes de Trabalho (pp. 323-344). Vila do Conde: Civeri Publishing.

Bourdieu, P. (1986). L'illusion biographique'. Actes de la recherche en sciences sociales, 62-63, 67-72. https://doi.org/10.3406/arss.1986.2317

Dubar, C. (1998). Trajetórias sociais e formas identitárias: alguns esclarecimentos conceituais e metodológicos. Educação \& Sociedade, 19, 62, 13-30. http://dx.doi.org/10.1590/ S0101-73301998000100002

Dubois, V. (1999). La vie au guichet. Relation administrative et traitement de la misère. Paris: Economica.

Duran, M.-J., Baril, R., Loisel, P., \& Gervais, J. (2008). Exploratory study on the discourse of an interdisciplinary team on workers : trajectories during a return-to-work programme. Perspectives interdisciplinaries sur le travail et la santé, 10, 2, 1-18. DOI: 10.4000/pistes.2232

Freire, J. (1991). Imigrantes, capatazes e segurança no trabalho da construção civil. Organizações e Trabalho, 5/6, 147-154. http://www.apsiot.pt/index.php/organizacoes-e-trabalho-n-5-6- 
dezembro-1991/61-revista-o-t/revista0506/283-joao-freire-imigrantes-capatazes-e-segurancano-trabalho-da-construcao-civil-pp-147-154

Gabinete de Estratégia e Planeamento (2010). Coleção Estatísticas - Acidentes de trabalho. Lisboa: Ministério da Solidariedade e da Segurança Social.

Gabinete de Estratégia e Planeamento (2017). Estatísticas em Síntese - Acidentes de Trabalho, 2015. Lisboa: GEP.

Goffman, E. (1983). The Interaction Order. American Sociological Review, 48, 1, 1-17. http:// www.jstor.org/stable/2095141_https://doi.org/10.2307/2095141

Goodwin, K. (2009). Designing for the Digital Age: How to Create Human-Centered Products and Services. Chichester: John Wiley \& Sons.

Hareven, T. \& Masaoka, K. (1988). Turning points and transitions : perceptions of the life course. Journal of Family History, 13, 3, 271-289. https://doi.org/10.1177/036319908801300117

Hélardot, V. (2006). Parcours professionnels et histoires de santé : une analyse sous l'angle des bifurcations. Cahiers internationaux de sociologie, 120, 59-83. http://www.cairn.info/article.php? ID_ARTICLE=CIS_120_0059 https://doi.org/10.3917/cis.120.0059

Hu, J., Jiang, Y., Liang, Y, Yu, I. T., Leng, H., \& He, Y. (2013). Predictors of return to work and duration of absence following work-related hand injury. International Journal of Injury Control and Safety Promotion, 21, 3, 216-223. https://www.ncbi.nlm.nih.gov/pubmed/23638695

Kaufmann, J. C. (1996). L’entretien compréhensif. Paris: Éditions Nathan.

Kosny, A., Lifshen, M., Pugliese, D., Majesky, G., Kramer, D., Steenstra, I., Soklaridis, S., \& Carrasco, C.

(2012). Buddies in bad times? The role of co-workers after a work-related injury. Journal of Occupational Rehabilitation, 23, 3, 438-449. https://www.ncbi.nlm.nih.gov/pubmed/23271499

Kotler, P. \& Armstrong, G. (2013). Principles of Marketing (6 $6^{\underline{a}}$ edição). Edimburgo: Pearson.

Laurel, B. (2003). Design Research: Methods and Perspectives. Cambridge: The MIT Press.

Lima, T. M. (2004). Trabalho e risco no setor da construção civil em Portugal: desafios a uma cultura de prevenção. Oficina do CES, n.․211. Coimbra: Centro de Estudos Sociais de Coimbra.

Lima, T. M. (2012). Acidentes de trabalho e experiências de sinistralidade: desafios à reparação e proteção social. In H. V. Neto, J. Areosa, \& P. Azeres (Eds.), Impacto Social dos Acidentes de Trabalho (pp. 323-344). Vila do Conde: Civeri Publishing. http://repositorium.sdum.uminho.pt/handle/ $1822 / 20091$

Magalhães, T. \& Antunes, I. (2012). Acidentes de trabalho. Avaliação médico-legal dos danos na pessoa. In H. V. Neto; J. Aresosa; P. Azeres (Eds.), Impacto social dos acidentes de trabalho (pp. 266-287). Vila do Conde: Civeri Publishing.

Martin, J.-C. \& Baril, R. (1995). L'exclusion comme effet de trajectoire administrative et de cheminement individuel. Lien social et Politiques, 34, 131-140. DOI:10.7202/005183ar

Mendes, J. M. O. (2003). Perguntar e observar não basta, é preciso analisar: algumas reflexões metodológicas. Coimbra: FEUC-CES. http://www.ces.uc.pt/publicacoes/oficina/194/194.pdf

Monteiro, B. (2017). Fogo que arde sem se ver: sofrimento social entre sinistrados no trabalho. Le Monde Diplomatique Edição Portuguesa - Dossier O acidente de trabalho não é o fim da história, 127, 8-9. 
Pereira, C., Santos, M., Cunha, L., \& Lacomblez, M. (2017). O regresso ao trabalho após o acidente sob o prisma do género. Le Monde Diplomatique Edição Portuguesa - Dossier $O$ acidente de trabalho não é o fim da história, 127, 10.

Pinto, J. M. (1996). Contributos para uma análise dos acidentes de trabalho na construção civil. Cadernos de Ciências Sociais, 15-16, 87-119.

Pinto, J. M. (2017). Impactos do acidente sobre a vida profissional: rendimentos, emprego e relações de trabalho. Le Monde Diplomatique Edição Portuguesa - Dossier O acidente de trabalho não é o fim da história, 127, 4-5.

Quériaud, C., Dugué, B., \& Petit, J. (2015). Les enjeux organisationnels de la reprise du travail de salariés après une longue absence. Perspectives interdisciplinaires sur le travail et la santé, 17-1, 1-24. http://journals.openedition.org/pistes/4469 https://doi.org/10.4000/pistes.4469

Rabardel, P. (1995). Les hommes et les techonologies: approche cognitive des instruments contemporains. Paris: Armand Colin.

Ramos, S. (2006). Envelhecimento, trabalho e cognição: do laboratório para o terreno na construção de uma alternativa metodológica. Tese de Doutoramento, Faculdade de Psicologia e de Ciências da Educação, Universidade do Porto, Portugal.

Rodrigues, V. (2017). As interações do sinistrado no trabalho com as instituições. Le Monde Diplomatique Edição Portuguesa - Dossier $O$ acidente de trabalho não é o fim da história, 127, 6-7.

Roxo, M. M. (2001). Segurança e Saúde do Trabalho: avaliação e controlo de riscos profissionais. Coimbra: Almedina.

Roxo, M. M. (2011). Direito da Segurança e Saúde no Trabalho: da prescrição do seguro à definição e desempenho. Coimbra: Almedina.

Santos, B. S., Gomes, C., \& Ribeiro, T. (2012). Os acidentes de trabalho nos tribunais portugueses. In H. V. Neto, J. Areosa, \& P. Arezes (Eds.), Impacto Social dos Acidentes de Trabalho (pp. 228-264). Vila do Conde: Civeri Publishing. http://repositorium.sdum.uminho.pt/handle/1822/20091

Siblot, Y. (2006). Faire valoir ses droits au quotidien. Les services publics dans les quartiers populaires. Paris: Presses de Sciences Po.

Stewart, A., Polak, E., Young, R., \& Schultz, I. Z. (2012). Injured workers' construction of expectations of return to work with sub-acute back pain: the role of perceived uncertainty. Journal of Occupational Rehabilitation, 22, 1-14. DOI: 10.1007/s10926-011-9312-6

Testenoire, A. \& Trancart, D. (2011). Parcours professionnels, ruptures et transitions. Inégalités face aux événements de santé. Centre d'études de l'emploi: Rapport de recherche, no⒌ http://www.ceerecherche.fr/publications/rapport-de-recherche/parcours-professionnels-ruptures-ettransitions-inegalites-face-aux-evenements-de-sante

Zaccaï-Reyners, N. (1995). Le monde de la vie: Dilthey et Husserl. Paris: Les Éditions du CERF.

\section{NOTAS}

1. Os dados mais recentes relativos a esta temática, disponibilizados pelo Gabinete de Estratégia e Planeamento - Ministério do Trabalho, Solidariedade de Segurança Social, reportam-se ao ano de 2015, e encontram-se sistematizados na publicação Acidentes de Trabalho - Coleção Estatísticas. 2. Vd., entre outros, Roxo (2001; 2011); Lima (2004); Pinto (1996); Areosa (2010; 2012); Freire (1991); Barros-Duarte e Cunha (2014). 
3. Vd., entre outros, Baril (2002); Durand, Baril, Loisel e Gervais (2008); Hu et al. (2013).

4. Vd., entre outros, Stewart, Polak, Young e Schultz (2012).

5. Vd., entre outros, Kosny et al. (2012).

6. Vd., entre outros, Durand, Baril, Loisel e Gervais (2008); Quériaud, Dugué e Petit (2015).

7. Sobre os acidentes de trabalho nos tribunais portugueses, ver Santos, Gomes e Ribeiro (2012), e sobre a avaliação médico-legal dos danos no sinistrado, ver Magalhães e Antunes (2012).

8. Sobre experiências de sinistralidade e desafios à reparação, ver Lima (2012).

9. Esta rutura pode ainda associar-se ao conceito de turning points, explorado nomeadamente por Hareven e Masaoka (1988), que diz respeito a mudanças percebidas subjetivamente pelos indivíduos como eventos que reorientaram a sua trajetória.

10. Os estudos sobre as bifurcações estão associados ao desenvolvimento de métodos longitudinais, estatísticos ou qualitativos, que permitem apreender a diversificação dos percursos dos indivíduos (Testenoire \& Trancart, 2011).

11. Projeto de investigação realizado por uma equipa multidisciplinar de psicólogos do trabalho e sociólogos, promovido, em 2016, pela Associação Nacional dos Deficientes Sinistrados do Trabalho (ANDST), e financiado pelo Programa Nacional de Financiamento a Projetos do INR-Instituto Nacional para a Reabilitação, I.P.

12. Para mais informação sobre estes instrumentos, ver Kotler \& Armstrong (2013), Goodwin (2009) e Laurel (2003).

13. Os mapas de percurso foram elaborados com recurso ao software Adobe InDesign.

14. Da análise dos dados, para além do Relatório Final do Projeto e de Seminários de apresentação de resultados, resultaram até ao momento as seguintes publicações: Monteiro (2017); Pereira, Santos, Cunha e Lacomblez (2017); Pinto (2017); Rodrigues (2017).

15. O principal instrumento de recolha de informação utilizado na referida investigação foi um inquérito por questionário que integrou diferentes vertentes de análise - as circunstâncias do acidente, as condições de emprego e de trabalho, os percursos institucionais e a multidimensionalidade dos impactos que deste decorrem (a nível pessoal, familiar, social, profissional). Contudo, ainda antes da conclusão da elaboração do mesmo, e para que pudesse haver uma aproximação prévia dos investigadores à realidade dos sinistrados e à multiplicidade de variáveis consideradas num processo pós-sinistro, revelou-se importante integrar uma dimensão qualitativa que auxiliasse, nomeadamente, na identificação de temas e perguntas que nele deveriam constar. o exercício reflexivo levado a cabo com a elaboração dos mapas de percurso viria a ter, assim, um papel importante no ajustamento da estrutura e no rigor e adequação das questões do inquérito por questionário.

16. A realidade da sinistralidade laboral afeta em maior número os homens e a grande maioria das incapacidades permanentes que resultam dos acidentes de trabalho são inferiores a $20 \%$. Foram entrevistados 6 homens e 4 mulheres. Dos 10 entrevistados, e no que respeita à atribuição das incapacidades, 5 tinham uma incapacidade permanente parcial inferior a 20\%, 2 tinham uma incapacidade permanente parcial superior a 20\%, 3 não souberam precisar. Em relação À situação perante o emprego, de entre os 10 entrevistados, 6 regressaram ao trabalho na mesma entidade patronal, um dos quais foi despedido um mês depois do regresso por não conseguir realizar as mesmas tarefas e outro solicita reforma por invalidez, depois de 6 meses a trabalhar; 4 encontravam-se desempregados (três deles de baixa no momento da entrevista e dois, simultaneamente, a aguardar a decisão do Tribunal do Trabalho), sendo que um deles foi despedido um mês depois do regresso e outro não viu o seu contrato renovado após o acidente de trabalho. 


\section{RESUMOS}

O presente artigo visa explorar um instrumento metodológico - mapas de percurso -, ilustrando a sua estrutura e os desafios e potencialidades associados à sua utilização. Os mapas de percurso foram concebidos no âmbito de uma investigação centrada na exploração das circunstâncias e consequências que os acidentes trabalho têm nos indivíduos e no processo do regresso ao trabalho, e assumiram uma função exploratória na análise de processos de reconstituição de experiências após um acidente de trabalho, com foco na compreensão do percurso institucional que os sinistrados percorreram. A sua utilização, no âmbito do estudo, permitiu conhecer e ilustrar as trajetórias e percursos dos sinistrados após um acidente de trabalho, através de uma reconstituição temporal de uma história e de um evento de saúde - o acidente - e uma melhor compreensão do seu impacto na vida dos acidentados (no percurso institucional, nas interações que tiveram, e nos sentimentos e emoções experienciados).

Este artículo tiene como objetivo explorar un instrumento metodológico - mapas de trayectoria ilustrando su estructura así como los retos y potencialidades asociados con su uso. Los mapas de trayectoria fueron diseñadas en el marco de una investigación centrada en el estudio de las circunstancias y las consecuencias de los accidentes de trabajo sobre los individuos y en el proceso de vuelta al trabajo. Sirvieron como instrumento exploratorio en el análisis de los procesos de reconstitución de experiencias tras un accidente de trabajo, permitiendo así entender las trayectorias institucionales recorridas por los accidentados. Su uso, en el marco del estudio, ayudó a identificar e ilustrar las trayectorias y las rutas de los accidentados tras un accidente de trabajo, gracias a la reconstitución temporal de una historia y de un evento de salud - el accidente - y permitió una mejor comprensión de su impacto en la vida de los accidentados (la trayectoria institucional, en las interacciones que tuvieron y en los sentimientos y emociones sentidos).

L'article explore un instrument méthodologique - les cartes de parcours - en présentant leur structure ainsi que les défis et potentialités associés à leur utilisation. Les cartes de parcours ont été conçues dans le cadre d'une recherche concernant les circonstances et des conséquences des accidents du travail sur les individus et le processus de retour au travail. Elles ont servi d'instrument exploratoire dans la reconstruction d'expériences après un accident du travail, en aidant à comprendre les parcours institutionnels des travailleurs accidentés. L'utilisation de la carte de parcours a permis, dans le cadre de l'étude, de connaître et d'illustrer ces trajectoires en recourant à la reconstitution temporelle d'une histoire et d'un épisode de santé - l'accident, ouvrant l'analyse à un meilleur entendement de son impact sur la vie des victimes (sur le parcours institutionnel, sur les interactions que ceux-ci ont connues et sur les sentiments et émotions ressentis).

This paper aims at exploring a methodological instrument - the accident journey charts -, depicting their structure and the challenges and potential related to their use. The accident journey charts were designed under the scope of a research which focused on the analysis of the circumstances and consequences the work accidents have on the individuals and on the back-towork process. Additionally, the accident journey charts took an exploratory role in looking at processes of reconstruction of experiences after a work accident, focusing on the institutional path the injured people had to follow. Their use, within the study, was determinant to reveal and depict the paths and journeys of the injured workers after an accident, through the temporal reconstruction of a story and a health event - the accident. It also contributed to a better 
understanding of the accident's impact on the injured workers' life (on the institutional path, on the interactions that took place, and on the feelings and emotions they have been through).

\section{ÍNDICE}

Keywords: work accidents, injured at work, paths, accident journey chart

Palabras claves: accidentes de trabajo, accidentados del trabajo, trayectorias, mapas de trayectoria

Palavras-chave: acidentes de trabalho, sinistrados do trabalho, trajetórias, mapas de percurso Mots-clés: accident de travail, sinistrés du travail, trajectoires, cartes de parcours

\section{AUTORES}

\section{CLÁUDIA PEREIRA}

Faculdade de Psicologia e de Ciências da Educação Universidade do Porto

Rua Alfredo Allen

4200-135 Porto Portugal cpereira@fpce.up.pt

\section{VANESSA RODRIGUES}

Instituto de Sociologia da Universidade do Porto

Faculdade de Letras

Universidade do Porto

Via Panorâmica Edgar Cardoso

4150564 Porto

Portugal vanessa.m.c.rodrigues@gmail.com 